\title{
Fissuras do real: desvios da mimese na dramaturgia brasileira contemporânea*
}

Elen de Medeiros $^{a}$

* Este texto é resultado parcial do projeto de pesquisa "Formulações estéticas do drama moderno brasileiro", em desenvolvimento, com financiamento ARDC/ PRPq/UFMG.

\section{Resumo}

Com base na abordagem de quatro obras, Apocalipse 1,11, do Teatro da Vertigem, Agreste e Projeto Body Art, de Newton Moreno, e Amores surdos, de Grace Passô, pretende-se reconhecer proposições de inserção de elementos desviantes do real ou do referencial de representação no teatro contemporâneo. Nesse sentido, as obras lidabym, cada qual com uma poética particular, com elementos estranhos que marcam desvios de comportamento, provocando assim um deslocamento quanto à composição da mimese teatral, e aproximam-se das percepções da realidade social em suas múltiplas marginalizações e formas de leitura.

Palavras-chave: dramaturgia contemporânea; desvios do real; mimese teatral; literatura dramática. 


\section{Mimese teatral e a realidade em cena}

Conceito controverso entre vários estudiosos do termo, a mimese teatral é aqui entendida como representação de uma suposta realidade em cena, valendo-se para tanto da construção verossímil dos elementos teatrais, a exemplo do que promoveram a dramaturgia e o palco realistas, que se mantiveram como paradigma de construção dramatúrgica por diversos períodos históricos. Auerbach (2002, p. 499) assim a definiu em seu Mimesis: "a interpretação da realidade através da representação literária ou 'imitação'", considerando que há, na história literária ocidental, vários modos de interpretação dos acontecimentos humanos. Se havia, entre os antigos, a regra clássica da diferenciação em níveis (elevado ou baixo), o realismo moderno rompe com esses preceitos e insere, em uma forma literária séria, a realidade cotidiana que só poderia ter lugar nas formas de representação baixa ou média. Afora essas duas maneiras, Auerbach ainda aventa uma terceira possibilidade estilística, que ele chama de realismo medieval, para o qual a doutrina dos níveis também não possuía validade.

No que diz respeito especificamente à teoria do teatro, em que o conceito de mimese será fundamento de grande parte da crítica e de avaliação das obras, o pensamento aristotélico é determinante para o que será tomado como molde: o mythos é a mimese da práxis. Nesse sentido, para Aristóteles, a "mimesis diz respeito à representação dos homens e, sobretudo, daquela [a representação] de suas ações" (PAVIS, 1999, p. 242).

Durante um período específico da história do teatro, mais particularmente a partir dos escritos de Diderot, que se manteve como paradigma apenas rompido naquilo que foi a encruzilhada naturalista-simbolista (SARRAZAC, 2012), essa representação era pautada pela construção de uma cena verossímil, em que a realidade cênica e dramatúrgica se assemelhava à realidade social: "É preciso mostrar a coisa como ela aconteceu: com isso o espetáculo não ficará senão mais verdadeiro, mais instigante e mais belo" (DIDEROT apud ROUBINE, 2003, p. 70). Usada com o intuito de apresentar virtudes ao seu público burguês, a mimese se mantém até o final do século XIX como um parâmetro de beleza e harmonia artística da obra, quando então a arte no Ocidente passa por uma crise da representação. 
Esse paradigma, que alicerçou o pensamento do teatro realista francês, encontra ecos na produção dramatúrgica brasileira na segunda metade do século XIX, particularmente com José de Alencar, que entende a peça teatral como um "daguerreótipo moral" em acordo com as normas morais do pensamento burguês nascente. Detendo-se mais precisamente na construção do texto de teatro, vemos que a estrutura dramática foi um dos maiores e principais elementos no teatro nacional e do qual nossos autores raramente se distanciaram. Ou seja, as bases do drama convencional, embora questionadas em alguns períodos da história do teatro nacional, pouco foram apagadas na formulação dramatúrgica, mesmo se tomarmos como referência autores-chave da compreensão de nossa modernidade teatral, tais como Nelson Rodrigues, Jorge Andrade, Dias Gomes, Gianfrancesco Guarnieri, Oduvaldo Vianna Filho e Ariano Suassuna.

Os fundamentos primordiais do drama, a exemplo do diálogo e da verossimilhança, sempre estiveram na base da poética de nossos dramaturgos, seja para poder alcançar o público de forma efetiva (Jorge Andrade, Guarnieri e Vianinha) seja para sua subversão e uso de ironia (tal como em Nelson Rodrigues). Isso nos leva a pensar que, de alguma forma, nossa dramaturgia não se distanciou efetivamente da construção mimética da cena, mesmo que possamos reconhecer movimentos de ruptura.

\section{Transfigurações do real ${ }^{1}$}

É aparentemente mais uma família normal, com seus problemas e relações cotidianas, composta pela Mãe, pelo Pai e os filhos: Joaquim, Samuel, Júnior - que vive no exterior -, Graziele e Pequeno. A cena transcorre na sala de estar de uma casa de família, de onde se nota, de um lado, "uma porta de entrada onde vê-se quem chega e quem sai. E a outra leva para os fundos da casa" (PASSÔ, 2012, p. 13). Ainda de forma

${ }^{1}$ Termo retirado da orelha do livro de Grace Passô (2012), utilizado por Kil Abreu, e que traduz nossa percepção dos recursos de que lança mão a autora. aparente, vivem mais um dia comum: eles têm problemas com os vizinhos, que fazem muito barulho no andar de cima, Joaquim é sonâmbulo, Samuel deve encarar seu primeiro dia de trabalho, Pequeno tem asma e Júnior liga do exterior para falar de sua saudade, da vontade de comer arroz com pequi. 
A Mãe cuida de tudo, alheia aos detalhes, e eles vivem em sua superficialidade cotidiana.

"Tem um hipopótamo dentro dessa casa".

A fala curta, rápida e precisa de Pequeno sobre a surreal presença de um hipopótamo no espaço privado da casa de família rompe com algo em Amores surdos. ${ }^{2}$ Numa primeira camada, irrompe uma estrutura simbólica, desviante do real por meio de sua transfiguração. Aparentemente, a peça assume uma convenção realista, que só na sua artificialidade pode ser aceita como tal. O espaço da casa, eminentemente o lugar primordial das peças burguesas, é o local da ação; do mesmo modo, podemos reconhecer a constituição familiar como estruturante para as narrativas do drama convencional. É essa a primeira ruptura que a fala de Pequeno provoca, na medida em que se desdobram, a partir de então, cargas simbólicas na forma assumida, dando vazão a uma forma de representação subjacente, marcada sobretudo pelo irreal ou surreal que é a presença do hipopótamo. Com esse simples desvio do caráter simbólico, a família e a casa assumem outras características, funções e conotações.

É então esta a segunda camada que se rompe com a frase de Pequeno. Rompe-se entre eles o aparentemente convencional, o jogo formal das relações frias do cotidiano, o distanciamento marcado pelas situações violentamente surdas do dia a dia. Quando, diante da presença do estranho, Joaquim ameaça matá-lo (o que significa voltar à ordem anterior), a Mãe se porta "digna, surpreendentemente forte" e impede qualquer gesto: "O GRANDE BICHO VAI CONTINUAR AQUI, NESSA CASA, DENTRO DE NÓS. DENTRO DE NÓS. NINGUÉM VAI MATÁ-LO. TEM COISAS QUE FORAM FEITAS PARA SE VIVER COM ELAS"3 (PASSÔ, 2012, p. 63).

"Tem coisas que foram feitas para se viver com elas", e não importa o quão ameaçadoras sejam e o quão estranhas pareçam. É justamente pelo desvio do real, pela marca do estranhamento que a peça vai se projetar para além do espaço privado e para além dos limites da sala de estar da casa. Diante

2 A peça, estreada em 2006 em Curitiba, teve seu texto finalizado apenas em 2009.

3 A caixa-alta é da própria dramaturgia. desse jogo provocativo, é possível estabelecer as relações entre o espaço do íntimo e o mundo exterior, entre os medos particulares e as representações do outro. É aí que tudo se rompe nessa dramaturgia. 
O íntimo se define como o mais interior e o mais essencial de um ser ou de uma coisa, por assim dizer, o interior do interior. O íntimo difere do secreto no sentido de que ele não se destina a ser ocultado, mas, ao contrário, destina-se a ser voltado para o exterior, extravasado, oferecido ao olhar e à penetração do outro que nós escolhemos. A dupla dimensão do íntimo atesta, aliás, a sua disposição de se oferecer em espetáculo (em condições, é verdade, restritivas): por um lado, relação com o mais profundo de si mesmo e, por outro, ligação estreita de si com o outro. (SARRAZAC, 2013, p. 21)

Nesse sentido, aquela aparente cena realista se quebra diante do leitor, na medida em que as pautas colocadas pela dramaturgia não estão circunscritas ao modelo convencional de representação da realidade, ou seja, à mimese teatral como largamente encarada. Antes, carregam em si as complexidades do que há para além das quatro paredes do universo privado.

\section{O kitsch como distorções do real}

Escrita para o terceiro espetáculo da Trilogia bíblica, do Teatro da Vertigem, Apocalipse 1,11 é assinada por Fernando Bonassi a partir de processo colaborativo: “Esta peça foi escrita em colaboração com o Teatro da Vertigem para a encenação de Antônio Araújo" (BONASSI, 2002, p. 186). O espetáculo, que foi desenvolvido no período de outubro de 1998 a janeiro de 2000, estreou em 24 janeiro de 2000, no presídio do Hipódromo, em São Paulo (cf. BONASSI, 2002).

Com base no livro bíblico Apocalipse, e articulando a ideia do fim dos tempos às questões pulsantes da sociedade no final do milênio a fatos chocantes que marcaram a última década do século XX, tal como o assassinato de 111 presos na chacina de Carandiru e o índio pataxó Galdino Jesus dos Santos queimado vivo em um ponto de ônibus de Brasília por jovens de classe média, a peça dilui o simbolismo bíblico entre as inúmeras referências do grotesco e da violência social brasileira, produzindo uma sequência de cenas que pulsam pelas imagens de um kitsch cultural. É assim que acompanhamos o percurso de João entre os meandros inóspitos do presídio, por onde vemos os desvios de uma sociedade segregadora e o juízo final de personagens-chave da cultura nacional: a Besta, uma drag queen; Babilônia, uma prostituta aidética; Talidomida do Brasil, 
uma jovem com má-formação dos membros cuja única fala é um trecho da Constituição Federal; a Noiva, que dá de "comer a quem tem fome"; um casal de sexo explícito etc. ${ }^{4}$

Para ajuizar e castigar as personagens desviantes social e moralmente, os Anjos Rebeldes e o Anjo Poderoso ameaçam, agridem e perseguem essas figuras marcantes até seu juízo final, quando têm sua punição. Em alguns momentos, as cenas são interrompidas pela entrada de dois palhacinhos e um coelho, que trazem a lume uma crise da representação em todo o espetáculo, interrompendo tanto a ação punitiva quanto o efeito desnorteante da boite New Jerusalém:

\author{
Juiz - Somos o que somos será porque sejamos \\ uma sub-raça, um país de mestiços, uma fusão de \\ elementos étnicos inferiores? Ou porque sejamos uma \\ nacionalidade em vidas de formação, o que explica o \\ estado de delinquência social do povo brasileiro? \\ Palhacinhos e Coelho (O Anjo Poderoso sai e traz os dois \\ Palhacinhos e o Coelho.) \\ Palhacinho 1 - (Para o Anjo Poderoso, que o empurra) \\ Você sabe com quem cê tá falando? Cê sabe de quem \\ eu sou parente? \\ Palhacinho 2 - Francamente! Isso é um absurdo! \\ Palhacinho 1 - Palhaçada. \\ Palhacinho 2 - Não é sério. \\ Palhacinho 1 - Que se foda... \\ Palhacinho 2 - É, eu também... tô cagando, viu! \\ Palhacinho 1 - Tem acerto? \\ Palhacinho 2 - Entra num acordo aí, porra... \\ Palhacinho 1 - Meritíssimo... um acordo... \\ (Palhacinho 1 passa um maço de notas ao Juiz.) \\ (BONASSI, 2002, p. 241)
}

\footnotetext{
4 Apesar de trazermos a s referência s dramatúrgicas, não podemos deixar de observar que tais aspectos são realçados pela cena: o casal de sexo explícito, por exemplo, faz sexo tendo ao fundo a música-tema de Ayrton Senna em suas vitórias na F-1. A Besta entra em cena carregando um bolo de aniversário para os 500 anos do Brasil. Babilônia veste uma camiseta do Flamengo rasgada e maquiagem exagerada e borrada, e assim por diante.
}

Nesse sentido, a peça produz níveis representacionais que se articulam na formulação de sentido social e simbólico. Se, num primeiro momento, o que salta aos olhos é o deslocamento dos referenciais míticos bíblicos para a realidade social brasileira, potencializando a denúncia e registrando uma primeira camada de representação, este foco é desviado continuamente por toda a dramaturgia com a inserção de elementos do kitsch, a exemplo dos dois palhaços e do coelho dizendo palavrões e corrompendo um juiz, e do grotesco midiático nacional (Chacrinha, Cid Moreira, Gretchen). Nesse momento, há novamente o deslocamento, agora para um segundo nível representacional, cada vez mais vertiginoso: 
A Besta canta Conga [by Gretchen] enquanto executa um
bailado trash, veado e demoníaco.
[...]
Babilônia entra. Começamos a ouvir música religiosa e as
primeiras palavras de Cid Moreira. (BONASSI, 2002, p. 206)

Essa rubrica assume uma dimensão mais pulsante na cena, já que o que ocorre com a entrada da Babilônia é uma cena de strip-tease tendo como fundo "musical" Cid Moreira narrando a Bíblia, em um disparate grotesco, tosco e desvirtuante, tanto da própria imagem do strip-tease quanto do referencial mítico bíblico.

Ou seja, existe uma ambivalência constante dos símbolos trabalhados ao longo da peça, entre o real potencializado pela violência e o kitsch contestador do real. Em ambos os casos, na formulação da dramaturgia de Apocalipse 1,11, ocorre um desvio da mimese, potencializado pela encenação, que repercute na percepção sobre a crítica à sociedade contemporânea por meio de uma espécie de estranhamento diante do que é exposto.

\section{Extratos de violência lírica}

Por outro lado, com forma poética bastante diversa, Newton Moreno causa essa fissura do real em suas peças Agreste (Malva-Rosa) e Projeto Body Art, com provocação, no entanto, semelhante. Para dar destaque às questões da homoafetividade e aos preconceitos que as circundam, ou seja, para dar voz a uma crítica acerca das questões do contemporâneo, o dramaturgo constrói peças que são marcadas pela intersecção entre o lírico e a violência (física, emocional), dando relevo a um estranhamento pelo choque e brutalidade do representado.

Em Agreste (Malva-Rosa), o texto de Newton Moreno articula dois registros cuja função é marcada propositalmente em virtude do jogo que deseja estabelecer entre o lirismo da relação amorosa e a agressividade da homofobia no sertão nordestino. A peça tem início com a presença de um narrador, a exemplo dos antigos prosadores do imaginário nordestino, que reúnem em torno de si seu público e, em um processo narrativo-memorialístico, desenvolvem a fábula. 
Um(a) narrador(a). Velho(a) contador(a) de estórias. Daqueles que reúnem um grupo ao redor da fogueira ou embaixo de uma árvore com uma viola/sanfona, pontua suas histórias com as músicas e acordes que saem de seu instrumento. Ele(a) recebe o público, dá o clima de cada passagem do texto, pausas, enfim, é o grande condutor da cena. (MORENO, 2004, p. 97)

Na primeira parte da peça, momento de aproximação e desvelamento do amor entre Ele e Ela, o registro é o narrativo: “CONTADOR(A): Ele andava muito para encontrá-la. Mas quando se viam, ficavam, no mínimo, a cinco metros de distância. Nem um centímetro a mais ou a menos. Exatos cinco metros. Sempre. Uma cerca os separava. Ela sorria de um lado, ele, do outro." (MORENO, 2004, p. 97)

Quando, no entanto, se descobre que Ele é na verdade uma mulher, o que causa escândalo, dada a relação homoafetiva, no pequeno vilarejo em que se instalaram para morar, surge uma onda de violência e intolerância, o que será marcado na estrutura dramatúrgica pelo registro dialógico.

O que notamos, ao longo da rememoração, é justamente o não lugar do estranho naquele sertão e o deslocamento da norma em confronto com o contexto hegemônico, que acaba sufocado pelo preconceito e pela ignorância. No entanto, para a composição da dramaturgia, o que se observa, na estruturação entre a narração e o dramático, é justamente o deslocamento da mimese provocada por inserções do lírico. Ou seja, o que promove o distanciamento fundamental diante da rememoração mimética, seja na construção narrativa, seja na formulação dramática, é o jogo que ambos os registros estabelecem com o lirismo da cena.

Menos amenizada é a marca da violência no Projeto Body Art. Composta por duas cenas distintas, A cicatriz é a flor e Dentro, ambas lidam com a violência, agora consentida, diante do corpo do parceiro: a primeira, uma tatuadora que registra frases no corpo da namorada; e a segunda, trazendo como protagonista um praticante de fist fucking. Ao colocar em discussão aspectos transgressores da normatividade sexual, o exercício dramatúrgico flerta com uma forma de representação que entra em conflito com o exagero da violência exatamente pelo registro lírico: 
NAMORADA (Off. Olhando o público, enquanto é cortada) Se eles pudessem ver o que eu sinto.

Ver minha vontade

Ver para fora da armadilha dos limites,

Ver que nasço outra com seu toque de lâminas.

(...)

Tatoo termina a cicatrização.

TATOO (Olhando o santo sudário em que marcou o corte da namorada)

Quantas peles eu tenho que rasgar para te ver nua?

Quem beijou teus dentes?

Quem te tirou a mordida, a presa morna, a fome úmida?

Onde perdeste a possibilidade do amor? (MORENO, 2005, p. 8-9)

A violência, consentida pelos parceiros e pulsante em todo o Projeto, fica sobressalente pelas curtas cenas em que é exposta: cortar a pele, fazê-la sangrar, rasgar o corpo nu, ferir o outro. São cenas de intensa exposição do corpo, precisamente do que é marcado como tabu, desviante do normatizado. No entanto, mesmo diante de exposição, a palavra lírica é responsável pelo contorno do jogo entre o corpo e a violência, a exemplo do que se nota na citação referida e na que segue:

Um HOMEM de meia-idade coloca uma luva comprida em uma das mãos, esticando-a até o antebraço. Luz até seu quadril. Cheira um 'poppers' (estimulante químico). Desce a mão com a luva abaixo do quadril. Parece que vai enfiá-la em alguém. Podese ouvir os gemidos de um rapaz, que num primeiro instante não vemos. São adeptos de 'fist-fucking', preparando-se para transa. Durante o texto, a mão vai desaparecendo mais e mais. Luz alterna-se entre homem e rapaz, nunca os focalizando juntos.

(...)

\section{RAPAZ}

Ele agarrou seu amante com firmeza. Rasgava-lhe os olhos, destemperado de gula no peito. Destroçava a construção de seu rosto, queria entender sua carne, decompô-la em lâminas ao sol para desfilar sua língua com força. Queria estudar o coração enquanto sugavalhe o suco e garimpava suas veias com os dentes. Ele escavaria toda aquela matéria até resgatar a si mesmo. (MORENO, 2005, p. 11 e 13) 
A força descritiva aqui é mais direta e contundente que em Agreste, mais agressiva, embora exista, na composição do texto dramatúrgico, o jogo premente já evidente na peça anterior, formulando a tríade homoafetividade - violência - lirismo. É com base nesse tripé que Newton Moreno põe em evidência, nas peças, justamente o que é considerado comportamento desviante, dando ensejo assim a questionamentos.

Com as obras de Grace Passô e Fernando Bonassi, os questionamentos propostos vão para além das questões sociais que pautam as peças, mas se consolidam também na formulação do texto, na elaboração de uma poética dramatúrgica, que assume contornos próprios a cada experimento, mas que coloca em debate novamente a mimese teatral.

\section{Deslocamentos finais}

A aproximação inusitada entre tais dramaturgias, com poéticas bastante distintas, foi pensada como eixo de reflexão sobre o lugar da mimese no teatro contemporâneo. As obras aqui referenciadas, mesmo que assumam uma forma de escrita distante uma da outra, seja pelos procedimentos adotados, seja pelo estilo dramatúrgico, têm em comum o fato de trazerem à discussão aquilo que é destoante, estranho diante das normas prescritas. Com essa proposição fundamental entrelaçando as peças de análise, o que se nota é uma crise da representação diante do contemporâneo. Como falar do que é extravagante, diferente ou estranho? Assumindo-o na própria forma.

A arte moderna, desde o final do século XIX, tem colocado em destaque a crise da representação: "Fragmentar, decompor, dispersar: essas palavras se encontram na base de qualquer definição de 'espírito moderno'. Entre a década de 1870 e o início da Segunda Guerra Mundial, a Europa assistiu a uma crise profunda no humanismo ocidental" (MORAES, 2002, p. 56). Especificamente na linguagem teatral, é entre o naturalismo e o simbolismo, a que Jean-Pierre Sarrazac (2012) chama de encruzilhada naturalista-simbolista, que são confrontadas as formas de representação, não como opostas - o naturalismo contra a pulverização simbolista -, mas como complementares diante das transformações sociais vividas e regentes das mudanças de perspectiva sobre o homem moderno. Essa crise da representação se coloca "como uma resposta às novas 
relações que o homem mantém com o mundo e a sociedade. Essas novas relações instalam-se sob o signo da separação" (SARRAZAC, 2012, p. 23). Trata-se, portanto, de colocar em xeque a imagem do "belo animal" aristotélico, cuja noção de belo era pautada pela organização simétrica das formas. Estamos falando de estruturas dramatúrgicas que se assumem monstruosas, a exemplo da parábola kafkiana “Um cruzamento:

Tenho um animal singular, metade gatinho, metade cordeiro. É uma herança dos bens do meu pai. Mas ele só se desenvolveu depois de ficar comigo, antes era muito mais cordeiro que gatinho. Agora no entanto possui, sem dúvida, características iguais dos dois. Do gato, cabeça e garras; do cordeiro, tamanho e forma; de ambos, os olhos, que são flamejantes e selvagens; o pelo macio e aderente à pele; os movimentos, que tanto podem ser pulos como gestos furtivos. (KAFKA, 2002, p. 98)

A dramaturgia moderna - e, por conseguinte, a contemporânea - coloca-se como a impossibilidade de composição uniforme e harmoniosa, provocando os elementos de sua estrutura em relação aos próprios deslocamentos vivenciados, psíquicos e/ou sociais.

O que vemos, em certa produção teatral das últimas décadas, a partir desses deslocamentos da mimese, não é mais uma criação da realidade em cena, mas um simulacro, seja pelo desvio da condição aristotélica de mimese, seja pelas rupturas provocadas na estrutura do drama em si.

Em $A$ república, Platão insiste sobre o gênero intermediário da arte rapsódica, compromisso entre mimese e diegese. Ora, bem parece que o teatro moderno e contemporâneo em seu conjunto esteja destinado a essa mimese incompleta e contrariada, a essa mimese sempre interrompida e cavalgada pela diegese. (SARRAZAC, 2017, p. 259)

O que queremos pôr em reflexão, na relação entre experimentos tão distintos, é essa condição da organização textual da dramaturgia contemporânea pelas "monstruosidades" apontadas (de caráter simbólico, social ou sexual). Ao trazer à baila essas discussões, elas irrompem na forma dramatúrgica como condição de questionamento de si mesma. Para dar conta das "monstruosidades" do contemporâneo, o que se considera como desvio da norma, parte dessa dramaturgia desloca a forma de representação, distante agora do pensamento 
mimético aristotélico, mas amparando-se na formulação de uma espécie de simulacro, por meio de simulações distorcidas do real. Se o real, conforme sentido dicionarizado, é aquilo que se apresenta como verdadeiro, nessas dramaturgias essa similitude é rompida exatamente neste ponto que se insere o que Sarrazac chama atenção, de uma arte rapsódica, num "entre-caminho" entre a diegese e a mimese. É, queremos pontuar, uma crise da representação do real, aproximandose, mas também distanciando-se dele, deslocando o que é representado para um jogo de ficção e recriação, alterando assim a construção de seus sentidos.

Parte da dramaturgia contemporânea, exemplificada aqui pelas obras abordadas, apoia-se nessa substituição, agora simulando e criticando o que se entende pela realidade (articulada por um discurso hegemônico), não mais a recriando à sua imagem verossímil. Não se distancia, no entanto, do elemento dramático para isso, mas articula-o a outros recursos, notadamente rapsódicos. É, não raro, uma "voz inquieta, errática, imprevisível. E, com frequência, subversiva. Uma voz anterior à do autor. [...] Voz do rapsodo, que retorna, que se imiscui na ficção" (SARRAZAC, 2017, p. 257), que se projeta na forma dramatúrgica contemporânea.

\section{REFERÊNCIAS}

AUERBACH, E. Mimesis: a representação da realidade na literatura ocidental. 4. ed. São Paulo: Perspectiva, 2002.

BONASSI, F. Apocalipse 1,11. In: TEATRO DA VERTIGEM [Vários autores]. Trilogia bíblica. São Paulo: PubliFolha, 2002.

KAFKA, F. Narrativas do espólio. Trad. Modesto Carone. São Paulo: Companhia das Letras, 2002.

MORAES, E. R. O corpo impossível: a decomposição da figura humana. São Paulo: Iluminuras, 2002.

MORENO, N. Agreste (Malva-Rosa). In: Sala Preta. v. 4. São Paulo; ECA/USP. p. 97 - 104, 2004. Disponível em: https:// www.revistas.usp.br/salapreta/article/view/57140/60128. Acesso em 25 de julho de 2018. 
MORENO, N. Projeto Body Art. Cópia mimeo. 2005.

PASSÔ, G. Amores surdos. Rio de Janeiro: Cobogó, 2012.

PAVIS, P. Dicionário de teatro. Trad. sob a direção de J. Guinsburg e Maria Lúcia Pereira. São Paulo: Perspectiva, 1999.

ROUBINE, J.-J. Introdução às grandes teorias do teatro. Trad. André Telles. Rio de Janeiro: Jorge Zahar, 2003.

SARRAZAC, J.-P (org.). Léxico do drama moderno e contemporâneo. Trad. André Telles. São Paulo: Cosac Naify, 2012.

SARRAZAC, J.-P. Poética do drama moderno. Trad. Newton Cunha; Jacó Guinsburg; Sonia Azevedo. São Paulo: Perspectiva, 2017.

SARRAZAC, J.-P. O futuro do drama. Trad. Alexandra Moreira da Silva. Porto; Campo de Letras, 2002.

SARRAZAC, J.-P. Sobre a fábula e o desvio. Trad. e org. Fátima Saadi. Rio de Janeiro: 7Letras/Teatro do Pequeno Gesto, 2013. 


\section{Abstract \\ Fissures of the real: deviations from mimesis in contemporary Brazilian dramaturgy}

From the approach of four theatrical pieces - Apocalipse 1,11 (Teatro da Vertigem), Agreste and Projeto Body Art (by Newton Moreno), and Amores surdos (by Grace Passô) -, we intend to recognize propositions of insertion of deviant elements of the real or the referential of representation in contemporary theater. In this sense, the works deal, each with a particular poetics, with strange elements that mark deviations of behavior, thus causing a displacement as to the composition of the theatrical mimesis, and approach the perceptions of social reality in its multiple marginalizations and forms of reading.

Keywords: contemporary dramaturgy; deviations from the real; theatrical mimesis; dramatic literature. 